\title{
Editorial: 50 Years of X-ray Mapping
}

In 1956 Duncumb and Cosslett developed the first imaging method capable of showing the location of elements in a solid with a spatial resolution of a micrometer. This technique was dubbed "X-ray mapping" probably because a separate image was used to show the presence or absence of each element within the field of view. Since its first demonstration, X-ray mapping has become one of the most popular and useful methods of X-ray microanalysis. It has been widely applied in areas of biology, chemistry, physics, geology, environmental science, and materials science.

This issue of Microscopy and Microanalysis commemorates the $50^{\text {th }}$ anniversary of the first X-ray map with a special section devoted to the history and future of this technique. The article by Friel and Lyman is a tutorial review, describing the development of the method for both bulk and thin specimens. Perhaps the most important recent advance is the collection and storage of an entire X-ray spectrum at each image pixel, forming a data cube called a spectrum image. The operator can mine this data cube for specimen information in a number of forms including X-ray maps of elements and phases. In the second paper, Newbury describes how the high-count-rate capability of the silicon drift detector is transforming X-ray spectral imaging and subsequent retrospective mapping. The third paper by Kotula et al. shows how tomographic threedimensional spectral images can be obtained by combining X-ray spectral imaging with automated specimen slicing via focused ion beam (FIB) milling. These authors then show how the data can be analyzed by advanced statistical methods. The stereo images of the Kotula article can be viewed with stereo glasses provided with this issue. These glasses can also be used to view animated versions of certain figures by clicking on the "supplementary materials" button for the Kotula article at the journal website: http:// www.journals.cambridge.org/jid_MAM. Electronic access information for subscribers is located on the back of the mailing label.

X-ray mapping has continuously evolved over the last 50 years. Each advance has allowed more information to be obtained from the specimen. It might be said that the ability to visualize data in this way has led to greater understanding of more specimens than any other form of microanalysis.

Charles E. Lyman Editor in Chief 